\title{
In Situ Measurement of Nanoscale Structural and Chemical Changes in Catalyst Nanoparticles under Reactive Environment
}

\author{
R. Sharma \\ ${ }^{1}$ Center for Nanoscale Science and Technology, National Institute of Standards and Technology, \\ Gaithersburg, MD 20899-6203
}

Catalytically active nanoparticles are an integral part of many industrial processes in the chemical and petro-chemical industries. Such particles are also employed in the synthesis of nano materials, such as carbon nanotubes and nanowires. Ex situ characterization of catalyst particles, before and after reaction, has typically been used to understand and measure their activity and lifetime. As the functioning and activity of catalyst nanoparticles depends on their structure and chemistry under reaction conditions, it is highly desirable to characterize their behavior in situ, under actual process conditions. During past decade, environmental scanning transmission electron microscope (ESTEM) has been successfully used to establish the relationship between the morphological, structural and chemical changes and the catalytic processes [1-4]. We have used this technique to reveal the structural and morphological changes that occur in different nanoparticles and determine how those changes control CNT nucleation and growth, as described below.

$\mathrm{Ni}$ and $\mathrm{Ni}-\mathrm{Au}$ catalyst particles were prepared wet chemical methods and by physical vapor deposition on $\mathrm{SiO}_{2}$ support on TEM grids. Fe particles were deposited on the same substrates using electron beam-induced decomposition of diriron nonacarbonyl $\left(\mathrm{Fe}_{2}(\mathrm{CO})_{9}\right)$ vapor. We use an ESTEM to record electron diffraction patterns, high-resolution images, energy-dispersive x-ray spectra (EDS) and electron energy-loss spectra (EELS) of the catalyst particles. The catalyst-support samples were heated to growth temperature $\left(500{ }^{\circ} \mathrm{C}\right.$ to $\left.700{ }^{\circ} \mathrm{C}\right)$ before introducing $4 \mathrm{~Pa}$ to $30 \mathrm{~Pa}$ of acetylene $\left(\mathrm{C}_{2} \mathrm{H}_{2}\right)$. High-resolution images were recorded at $\approx 10$ frames $\mathrm{s}^{-1}$. Molecular dynamics simulations and density functional calculations were used to explain the experimental results.

High-resolution images revealed that formation of metal carbide structures preceded CNT nucleation and growth. In case of $\mathrm{Fe}$, the catalyst structure was identified as $\mathrm{Fe}_{3} \mathrm{C}$ for active (Figure 1a) and $\mathrm{Fe}_{2} \mathrm{C}_{5}$ for inactive (Figure 1b) particles, respectively. Lattice spacings in high-resolution images of $\mathrm{Ni}-\mathrm{Au}$ nano particles (Figure 2), recorded during CNT growth at $520{ }^{\circ} \mathrm{C}$ in $10 \mathrm{~Pa}^{\circ}$ of $\mathrm{C}_{2} \mathrm{H}_{2}$, also matched a carbide $\left(\mathrm{Ni}_{3} \mathrm{C}\right)$ structure. EDS spectral images of an active Au-Ni particle (Figure 2c), recorded after CNT growth, show the particles to have Au rich tip and Ni rich base. CNT were observed to attach and grow from the Ni rich base. Figure 3 a shows a sequence of high-resolution images of Ni-Au nano particle, extracted from a video recorded at $520{ }^{\circ} \mathrm{C}$ in $10 \mathrm{~Pa}$ of $\mathrm{C}_{2} \mathrm{H}_{2}$. First, the carbon layer attached to the surface of the catalyst particle, and then started to split from the top left corner. Further lift-off and growth is accompanied by flattening of the top. The processes is repeated and in the course of the carbon dome lift-off, the particle shape alternates between flattened or rounded; before the particle facet becomes covered by carbon atoms under the dome and the formation of the next carbon dome occurs, the particle shape again becomes more faceted. The process repeats in the course of each new tubular structure formation, following the same lift-off mechanism. Measured distances (Figure 1b) between nucleating tube and Ni particle surface (as explained in the inset) were plotted to measure the dynamics of the particle shape change. Detailed analysis of the relationship between catalyst structure, surface plasmon and CNT nucleation and growth will be presented.

\section{References}

[1] P. Hansen et al., Science 224, 1508-1510(2001).

[2] S. Helveg et al., Nature 427, 426 (2004).

[3] Yoshida et al., Nano Letters 9, 3810-3815 (2008).

[4] R. Sharma, J. Mater. Res. 20, (2005) 1695. 
[5] Contributions from See Wee Chee, Peter Rez Andrew Herzing, Boris Yakobson, and R. Harutyunyan are gratefully acknowledged.
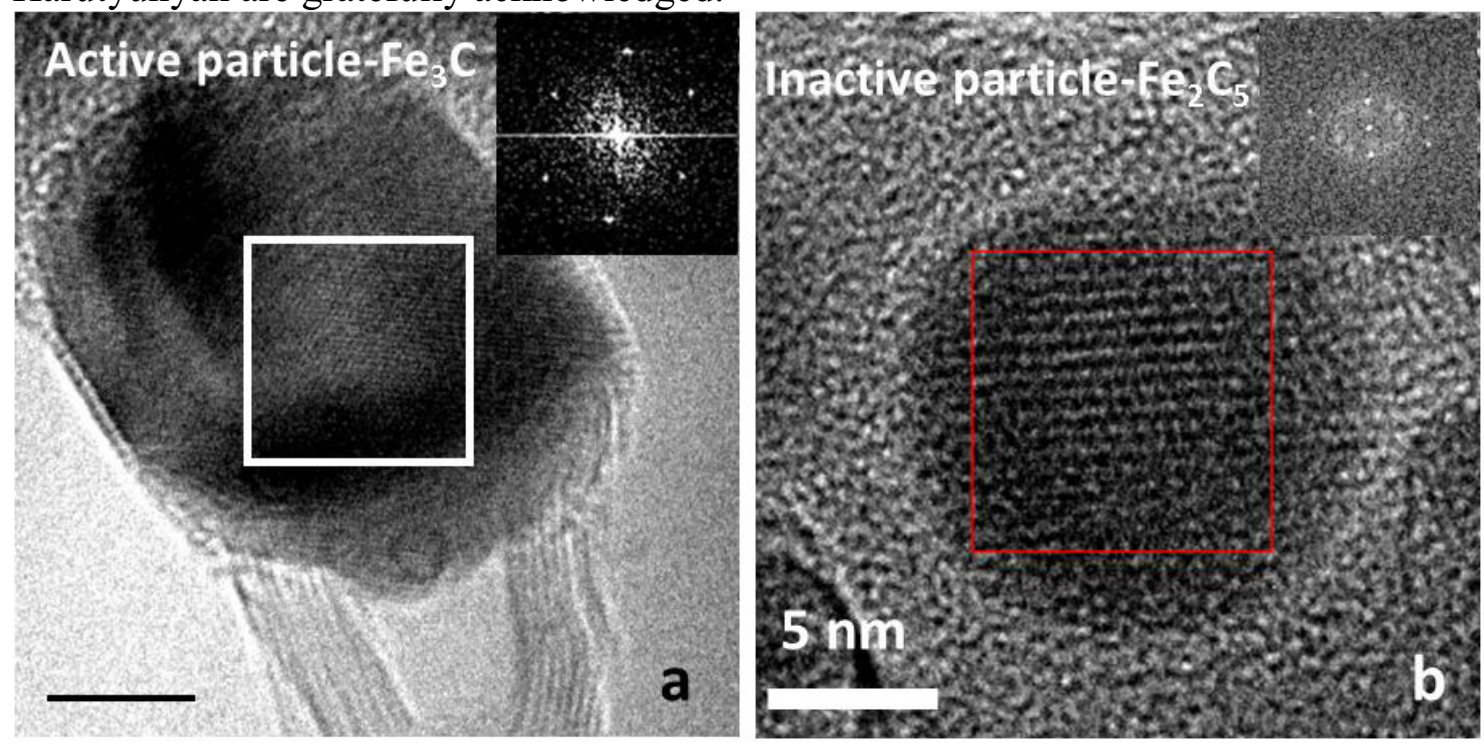

Figure 1. High resolution images extracted from videos recorded at $650{ }^{\circ} \mathrm{C}$ in $4 \mathrm{~Pa}$ of flowing $\mathrm{C}_{2} \mathrm{H}_{2}$ during CNT growth. (a) Lattice spacing, measured from the fast fourier transform (FFT) of the boxed region (inset in the upper right hand corner) matched the $\mathrm{Fe}_{3} \mathrm{C}$ structure, while (b) the measured spacing for the inacive particle matched the $\mathrm{Fe}_{2} \mathrm{C}_{5}$ structure.

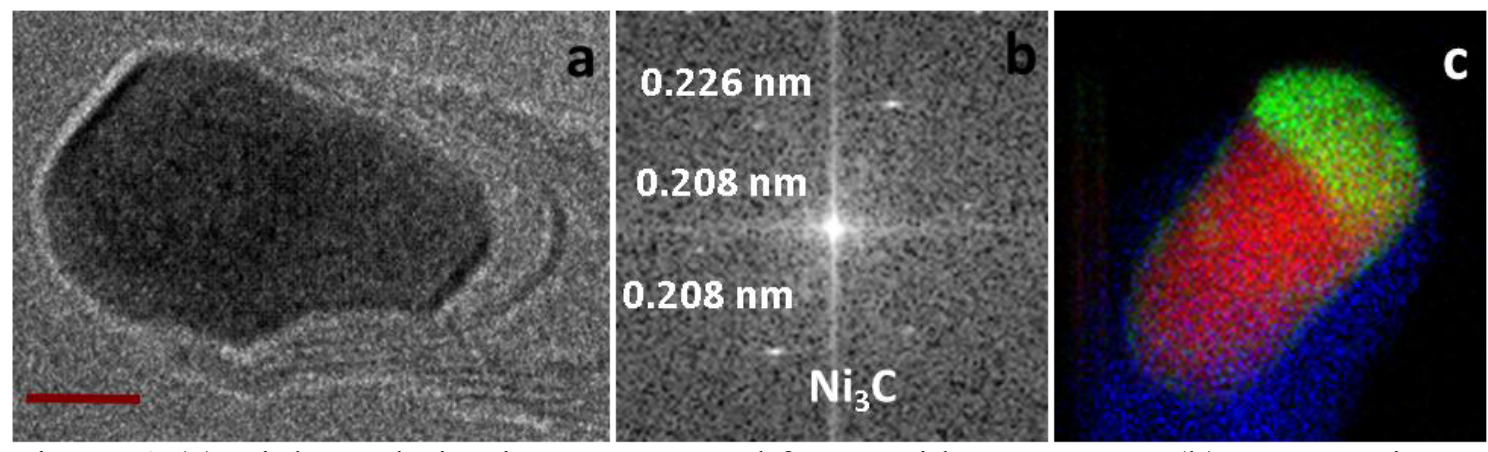

Figuure2 (a) High resolution image extracted from a video sequence, (b) Fast Fourier transform (FFT) of the image, (c) EDS Spectral image showung Au rich (green) top and Ni rich (red) base of the Ni-Au particle active for CNT growth. Note CNT (blue) are mainly attached to the base area.

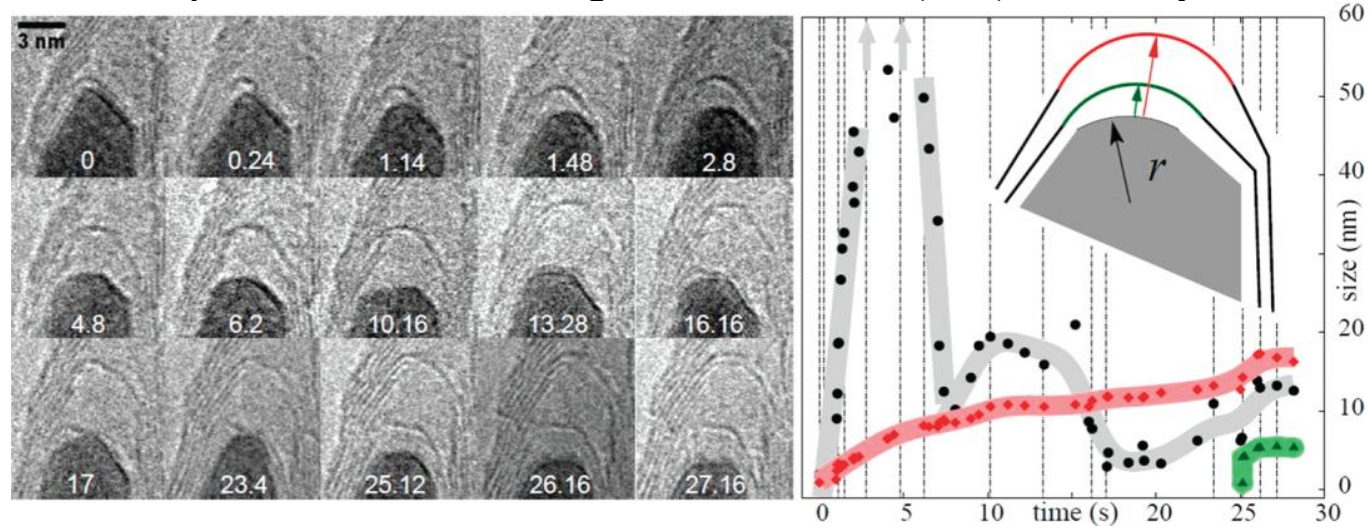

Figure 3. Evolution of catalyst morphology during CNT nucleation and growth process showing that lift-off of a CNT is accompanied particle shape change (left). The measured dynamics of key dimensions (inset) from the sequence of TEM images are used to model the growth dynamics. 